\title{
Memorias compartidas: desarrollo de la imagen
}

\section{Shared memories: development of the image}

\author{
TIPO DE TRABAJO: Comunicación virtual.
}

PALABRAS CLAVE

Reconstrucción de memorias, Pictórica, Proceso colaborativo, Imagen.

KEY WORDS

Reconstruction of memories, Pictorial, Collaborative process, Image.

RESUMEN

Esta investigación, aún en marcha, tiene como objetivo la realización de una serie de diez pinturas, cuya poética destaca la reconstrucción de memorias personales. El trabajo fue formulado colaborativamente, partiendo de relatos sobre objetos particulares de personas, familiares o amigos afectivamente significativos, que estuvieron ligadas al artista en distintos períodos y lugares. Las descripciones de estos individuos sobre sus memorias de estos objetos amplían y resignifican el sentido de la palabra familiar cuando se aplica a los propios objetos. Las experimentaciones pictóricas fueron producidas partiendo sólo de relatos subjetivos enviados al artista vía e-mail o redes sociales. Este procedimiento hizo posible la materialización de la imagen desde su recreación. Para la exposición de los trabajos se utilizó un monóculo de madera, que propicia la mediación de estas experimentaciones pictóricas, estableciendo un distanciamiento entre la pintura realizada y el espectador, desencadenando una fundamental distancia entre el tiempo vivido y el tiempo presente, ahora resignificado, así como discusiones sobre el tiempo, cuando la distancia y la proximidad se han confundido. La participación colaborativa en esta acción poética ha potenciado la investigación y la reflexión sobre la creación de nuevas imágenes en la contemporaneidad.

\section{ABSTRACT}

This research that still in progress, aims to carry out a series of tem paintings, whose poetics highlights the reconstruction of personal memories. The work was formulated collaboratively, starting from stories about peoples, relatives or emotionally significant friends personal objects, who were linked to the artist in different periods and places. The descriptions of these individuals about their memories of these objects broaden and resignify the meaning of the familiar word when applied to the objects. The pictorial experiments were produced based only on subjective stories sent to the artist via e-mail or social networks. This procedure made possible the materialization of the image from its recreation. For the exhibition of the works, a wooden monocle was used, which facilitates the mediation of these pictorial experiments, establishing a distance between the realized painting and the spectator, unchaining a fundamental distance between the lived time and the present time, now resignified, as well as discussions about time, when distance and proximity have been confused. Collaborative participation in this poetic action has fostered research and reflection on the creation of new images in the contemporaneity.

[...] sólo el arte es posible, porque es siempre la presencia de una ausencia, porque es su misión mostrar lo invisible, por medio de la fuerza organizada de las palabras y de las imágenes, juntas o separadas, el arte es el único modo de hacer sensible a lo inhumano. (Rancière, 2018:46). 


\section{INTRODUCCIÓN}

Este artículo presento aspectos de la investigación "Memorias compartidas: desarrollo de la imagen", todavía en marcha, que desarrollo en el Máster en Artes Visuales de la Universidad Federal de Santa María (Brasil). A partir de un trabajo colaborativo en las Artes Visuales, trato de reflexionar acerca de las relaciones entre memoria, objetos afectivos, resignificación en la pintura hoy.

Ante todo, es imprescindible relatar el proceso ocurrido anteriormente a este texto, señalando puntualmente lo que me motivó como artista e investigador hasta llegar al direccionamiento de la investigación que actualmente desarrollo. El período entre 2012-2017, fue permeado por experiencias en los medios gráficos y pictóricos oriundos de investigaciones que estaban relacionadas a memorias personales. A lo largo de ese tiempo he establecido relaciones entre esas memorias que eran resultantes de la imaginación y de referenciales fotográficos personales, los cuales vinieron a materializarse a través de pinturas, grabados y libros de artista. En estas formulaciones se destacaba sobre todo aquello que considero íntimo, relacionando a ese concepto las personas, objetos y lugares.

Se trataba de transitar en una narrativa personal, para reconstruir algunas memorias que rescaté de cuando niño en la casa de mis abuelos. De ese período de niñez me recuerdo manipulando a los guardados personales familiares donde había muchas fotografías y junto a ellas la presencia del monóculo (Ilustración 1). Este pequeño objeto me encantaba, lo encontraba como algo fascinante, me acuerdo de la experiencia de poder ver algo en el interior de aquel objeto, una imagen más allá de aquella pequeña lente, y ese recuerdo fue sin duda el punto inicial que ha generado la profundización de esta nueva investigación.

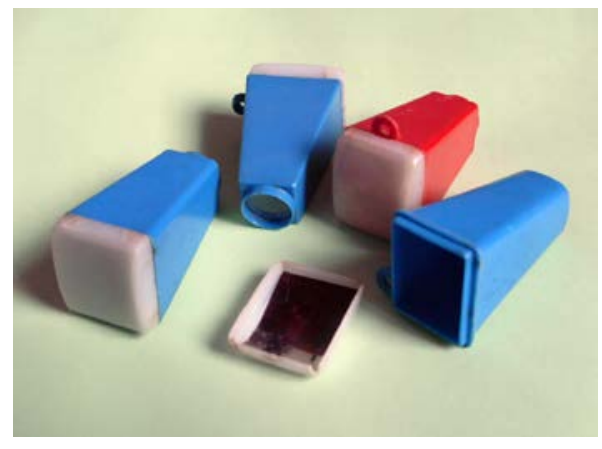

Ilustración 1. Monóculos antiguos. En <https://bit.ly/2EhquqO $>$.

A partir de este pequeño objeto, el monóculo, pasé a resignificar la palabra familiar, ampliando la investigación e involucrando la relación íntima de otras personas a sus objetos afectivos. Esa resignificación procedió de estudios realizados sobre memoria con Peter Burke y prácticas colaborativas en el arte contemporáneo con Sophie Calle y Cildo Meireles. Las lecturas que abordan sobre procesos de creación, las clases, los encuentros de orientación o visitas en exposiciones, todo añadió para la formación del pensamiento que ahora desarrollo acerca de esta investigación. Que es el alma de las cosas.

En latín hay la expresión: animan rerum, que significa el "alma de las cosas", percibo un poco de esa característica afectiva y de cierto modo espiritual que algunos objetos poseen, es decir, cuando se hace la referencia a un objeto de afecto, a un objeto a lo cual hemos atribuido especial significado. Recordamos con tanto cariño a determinados objetos, y que a los ojos de otros parecen sencillamente objetos inertes. Esto se asemeja al ciclo de la vida que es el crecer, desapegar - deshacerse de cosas menores, a veces hasta olvidadas. Sin embargo, corresponde también al tener, poseer objetos, pero que por veces están cargados en lo más íntimo de recuerdos, de pequeñas acciones, gestos, personas, rinconcitos.

A esa memoria afectiva asociada a objetos personales, he asociado la propuesta poética que vengo desarrollando y que me ha permitido transitar en el tiempo a partir de relatos subjetivos, colaboraciones, de personas que marcaron momentos significativos en mi propia trayectoria de vida, y que demarcan tres instancias:

\section{Personas: que pasaron / pasan por mi vida;}

\section{Objetos: que me remiten los más variados recuerdos;}

3. Lugares: que activan en mi memoria algún sentimiento familiar o de acogida.

Para eso la investigación está siendo formulada colaborativamente, partiendo de relatos sobre objetos particulares de familiares, o amigos o personas afectivamente significativas, que estuvieron presentes en mi vida en diferentes períodos y lugares. Para ello, he 
utilizado emails, redes sociales, paradoxalmente los medios tecnológicos donde la comunicación se establece rompiendo barreras del tiempo y espacio, y que se mostraron rápidos y eficientes.

A partir de esos relatos escritos, empiezo la materialización de la imagen de los objetos, a partir de su recreación en la superficie tramada del lienzo, o sea, a través de la pintura. Eso permite que yo utilice el proceso pictórico como medio y al mismo tiempo como lugar de investigación, ya que a lo largo de este proceso vengo descubriendo nuevas vías, nuevos medios, nuevas motivaciones que desconocía hasta entonces.

Una de ellas es el uso del monóculo, incorporado como objeto físico de la investigación. Lo que le ha convertido vital importancia para el trabajo ya que me ha permitido establecer la distancia entre el pasado y el presente, así como propiciado reflexiones acerca del tiempo, cuando distancia y proximidad se mezclan.

\section{METODOLOGÍA}

Desde que me conciencié sobre lo que vendría a ser abordado en esta investigación, debido al hecho de que es una investigación pautada en el proceso, ante acciones que suceden en el cotidiano, la única certeza que tuve era que el trabajo ya se había iniciado, era así como estar en un sitio familiar, pero teniendo una mirada atenta a lo desconocido.

Por lo tanto, para desarrollar esa investigación me apoyo en el enfoque poiético según lo cual las acciones de ir y venir en el proceso de creación relacionan se con el pensar, es decir, los esbozos, proyectos y lecturas inter actúan mutuamente en ese abordaje. Desde el proyecto inicial hasta ahora la investigación fue subsidiada por esa metodología, lo que ha posibilitado un orden de ideas en la medida en que el proceso se va desarrollando y el trabajo va suscitando diferentes modos de continuidad a lo que está siendo investigado.

Así es de gran importancia mencionar el pintor y filósofo René Passeron, que haciendo uso del concepto inicial de Valéry (1937) aplicado a la poesía; lo extendió a todas las demás artes. Y al tratarse específicamente de las experiencias poéticas en pintura, las contribuciones de Passeron ${ }^{1}$ (2004) posibilitan esa libertad en el modo de pensar del artista que, partiendo de la sensibilidad es conducido por la poiética. Por lo tanto, "[...] es el pensamiento posible de la creación [...]" (p. 10). Para la concreción de una experimentación pictórica, el hacer es necesario para entonces haber la reflexión sobre el proceso de ejecución. Luego lo que lleva al artista a comprender su producción está constantemente articulado a las acciones del hacer y pensar.
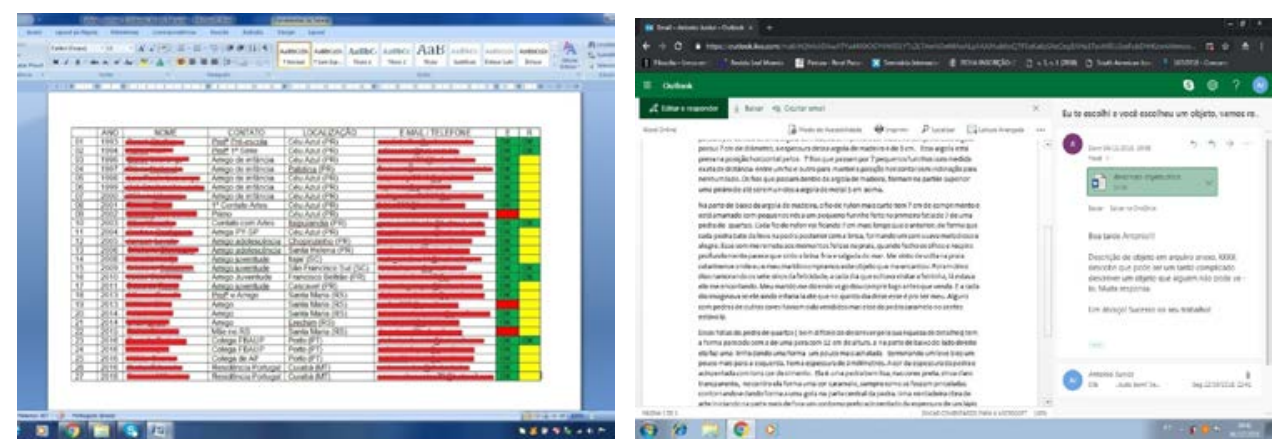

llustraciones 2 y 3. Lista de invitados para la propuesta y E-mail con la respuesta de un invitado. Fotos del autor.

Y para potenciar esa poética busco otro tiempo, otras memorias, pero tratando de establecer conexiones con vínculos afectivos que estuvieron o están directamente ligados, al pasado y al presente. Sea como artista o investigador, grande parte de mi construcción como persona y profesional está formada por una red de personas, de diferentes tiempos y locales. Del mismo modo como tengo un afecto particular por cada uno de los sujetos elegidos a colaborar con la investigación, imagino que cada uno de ellos tiene algún vínculo afectivo a un objeto personal que tenga o haya tenido a lo largo de la vida. Así pues, he tomado como parámetro para ese trabajo referencias "objectuales" asociadas a personas, eventos, relaciones, en última instancia, memorias que de forma particular han influido en la constitución de este recorrido personal que se refleja en la investigación poética.

\section{DESARROLLO}

\footnotetext{
${ }^{1}$ PASSERON, René. A poiética em questão. In: Revista Porto Arte. Porto Alegre, v. 13, n. 21, 2004.
} 
Esta opción se justifica en gran parte por la ampliación del espectro de las memorias, de lo que fue significativo e impregnó esa trayectoria, en pleno movimiento. Entre tantos aspectos importantes, he empezado por definir una relación de los nombres de personas que tuvieron / tienen alguna relación cercana, quienes todavía siguen activos en mi memoria, especialmente cuando reflexionamos acerca de lo paso de los años. En esa relación he enumerado a sujetos como: la primera profesora de la educación infantil, el mejor amigo de infancia, la persona que me acercó a un primer contacto con las artes, etc. Y he establecido contacto inicial con cada una de ellas. Los contactos fueron realizados por e-mail, teléfono e incluso personalmente, dado que los sujetos viven en diferentes localidades de Brasil y del exterior. En este proceso de aproximación ha pasado también otro tipo de contacto que actualmente no es muy utilizado, que es el envío de cartas, medio de comunicación muy usado hace décadas atrás.

Sin embargo, la interfaz más directa y rápida fue a través del uso de ordenadores y teléfonos móviles, lo que propició además un acercamiento del investigador a los sujetos colaboradores, ya que ha permitido reflejar algo sobre cómo vivo, cómo me relaciono y cómo me comunico, parte del cotidiano contemporáneo en lo que vivimos. A partir del contacto inicial, he lanzado a cada una de esas 27 personas un cuestionamiento/invitación "¿Yo te elegí y tú eliges un objeto, vamos a reconstruir memorias?".

He solicitado que cada una de ellas describiera con bastante minucia algún objeto perteneciente a sus "memorias afectivas". He mencionado que el texto, debería contener algún significado, vivencia, historia, cuestiones afectivas relativas al objeto mencionado, o incluso el despertar de alguna memoria. Sugerí algunas preguntas para facilitar la construcción de los relatos, así estaría repleto de características físicas, como: color, tamaño, forma y detalles.

A lo largo de ese proceso, constituido inicialmente por veinte y siete (27) personas, he obtenido respuestas a la invitación colaborativa de apenas diez (10) sujetos. De acuerdo con la metodología poiética, eso hace que yo proceda a una reorganización de ideas en el proceso, lo que significa hasta el momento, que tendré de dirigir mi mirada solamente a los relatos recibidos, descartando la posibilidad de realizar una clasificación de los textos enviados.

\section{DISCURSIVO}

En el proceso de realización de las pinturas, comienzo con la lectura de cada relato, subrayando todas las palabras que considero relevantes en el texto, para entonces formar una imagen y constituir bocetos. Constato que los relatos poseen descripciones muy variadas, desde colores y formas distintas hasta complexas relaciones contextuales, en el cerebro busco imágenes y colores a partir de lo que ya está construido en la propia memoria. Los primeros experimentos se realizan en tinta gouache, también he insertado una ventana de papel en la búsqueda de distintos encuadramientos parciales de los objetos, lo que puede proporcionar una nueva interpretación de la imagen para el público.
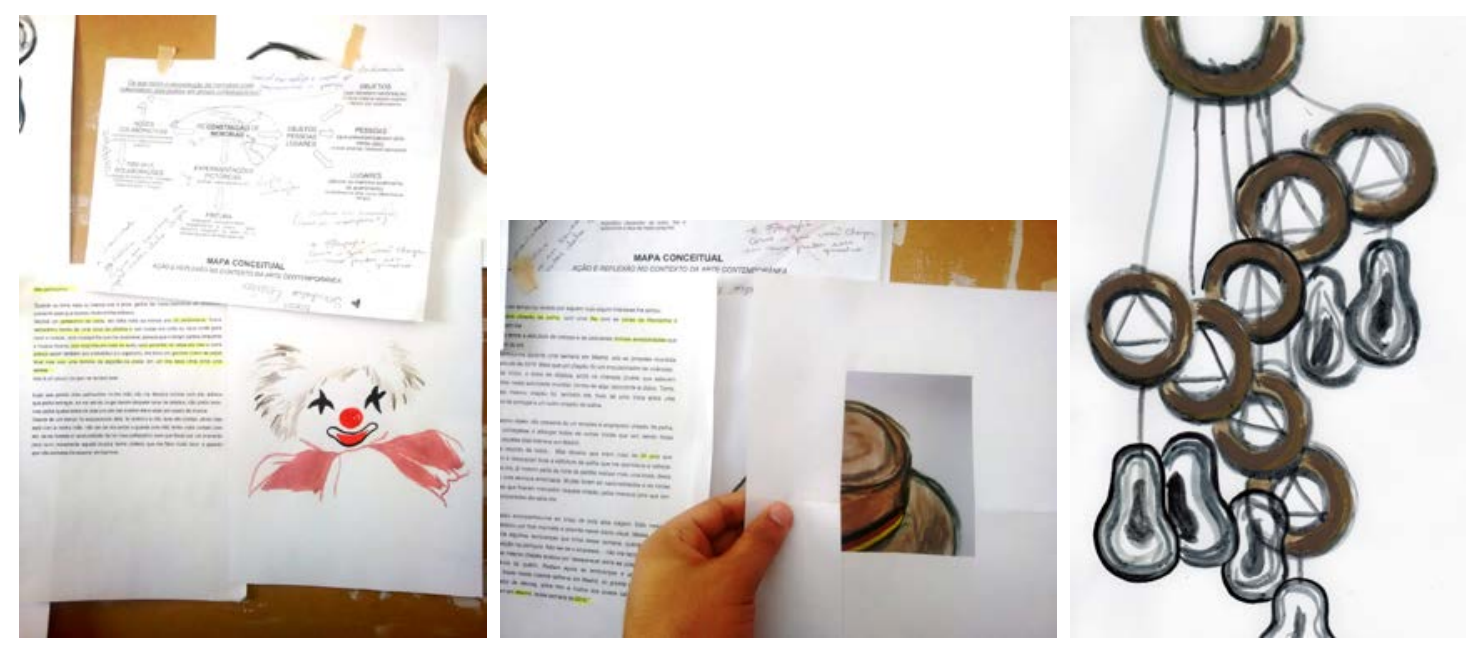

llustraciones 4, 5 y 6. Proceso de elaboración del proyecto a partir de los relatos. Fotos de los autores.

Al realizar esos proyectos, siento la necesidad de repetir y estudiar varias veces la misma imagen dirigiendo ese estímulo hasta casi el agotamiento. Cuando es provocada la sensación de que algún boceto se aproxima al relato recibido, empiezo la pintura al óleo sobre el lienzo. Ese proceso no es necesariamente fijo, pero de modo involuntario percibo el desarrollo de esa dinámica creadora.

\section{CONCLUSIONES}


Esa investigación sigue en construcción y tiene fomentado discusiones acerca de la materialización de la imagen mediada a través de colaboraciones escritas, lo que cruza memorias, contextos y tiempos - de los sujetos y de lo investigador.

Al realizar las pinturas de los objetos, a partir de las descripciones que recibí de algunos sujetos que muy pronto colaboraron, he percibido la inserción de cuestiones culturales que ciertos objetos poseen, cultura que esa que cambia de un lugar a otro, y que puede comunicar algo, tal como Burke $^{2}$ (2017) dice "[...] una ventaja particular del testimonio de imágenes es la de que ellas comunican rápida y claramente los detalles de un proceso complejo que un texto tardaría mucho más tiempo para describir, y de forma más vaga [...] "(p. 125).

Cuando empiezo a aprehender elementos contenidos en el texto proporcionado por los colaboradores, percibo lo cuánto la imagen generada esta indirectamente asociada a la cultura en la cual el objeto estaba inserto, porque los detalles de los objetos hacen que se establezca cierto tipo de asociación dando les ese recuerdo cultural, propuesto por Burke. En este sentido, se construyen nuevas relaciones, motivaciones desconocidas hasta entonces. Como fue el descubrimiento del cuia de mate.

Esta investigación sigue en marcha y su desarrollo está pendiente de los relatos que van llegando. Simultáneamente a ejecución de las pinturas, son confeccionados algunos monóculos en grande escala, objetos que ayudarán a constituir el relato y la ambientación expositiva con vistas a las reflexiones en torno a la reconstrucción de las propias memorias, las ajenas y la inserción de cuestiones acerca de esos objetos.

El proceso que se está constituyendo forma parte de mi formación como artista / investigador. En este sentido, se trata de una pequeña parte de lo que viene siendo desarrollado y ponderado por reflexiones, lo que ciertamente será ampliado tanto en lo que se refiere a los aspectos del lenguaje pictórico en la contemporaneidad, aliada a diversos modos expositivos, en cuanto a lo que se refiere a los nuevos medios de construcción y reconstrucción de imágenes. Tales experimentaciones y colaboraciones proporcionan un acceso democrático para la elaboración del proceso creativo, haciendo que se cree un banco de imágenes, no sólo de la narrativa aislada del autor, sino apuntando algunas evidencias históricas a través de toda imagen y la cultura material que permanece oculta.

Abordar tales temas a través de la pintura, también implica en la discusión sobre la memoria misma del arte, pues la historia es pautada por referenciales pictóricos donde explana sobre distintos tiempos. Tal como se refiere el pintor Giannotti ${ }^{3}$ (2009): “... ante todo, debemos aprender a situarnos en el tiempo, creyendo que el artista todavía tiene algo que decir sobre su experiencia al mundo (16)". Problematizar la investigación en pintura es pensar en nuevas posibilidades para el arte contemporáneo. Este movimiento de ir y venir en las acciones de los procesos en pinturas, tras consigo cuestiones pertinentes a los actos reflexivos en torno a sus acciones, $y$ acentúa su colaboración con la sociedad actual.

\section{FUENTES REFERENCIALES}

Burke, P. (2017). Testemunha Ocular: o uso de imagens como evidencia histórica. 1.ed. São Paulo: Editora Unesp.

Giannotti, M. (2009). Breve História da Pintura Contemporânea. 2.ed. São Paulo: Claridade.

Passeron, R. (2004). A poiética em questão. In: Porto Arte. Porto Alegre, 13(21).

Rancière, J. (2018). Figuras da História. 1.ed. São Paulo: Editora Unesp.

\footnotetext{
${ }^{2}$ BURKE, Peter. Testemunha Ocular: o uso de imagens como evidencia histórica. São Paulo: Editora Unesp, 2017.

${ }^{3}$ GIANNOTTI, Marco. Breve História da Pintura Contemporânea. 2.ed. São Paulo: Claridade, 2009.
} 